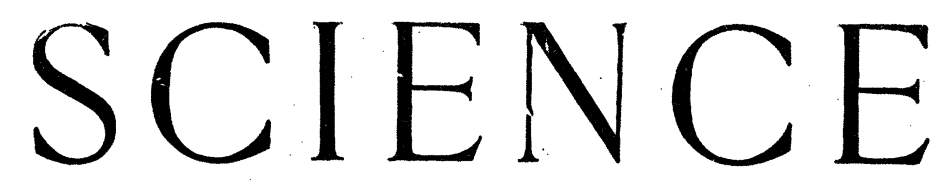

NEW YORK, MARCH I6, I894.

\section{ON THE ORIGIN OF ANCIENT QUARTZ ROCKS.}

BY J. F. BLAKE, LONDON, ENGLAND.

THE abundance of large masses of tolerably pure quartz which occur in various conditions in some of the oldest formations is a remarkable circumstance which it has not yet been, I think, attempted to explain. Some of them may be put down in the first instance, though without exhausting our enquiry about them, as sandstones, as for example the "original "Huronian quartzites and the Potsdam sandstone and the quartzites of Shropshire, Sutherlandshire; others, particularly when they are gold bearing, are called reefs, which may or may not be parallel to the stratification of the surrounding rocks. 'These are well known to characterize the older formations in all parts of the globe. In Great Britain, as at Connemara in Ireland and Schiehallion in Scotland, there are large nearly isolated masses of white quartzite in Precambrian rocks, and, elsewhere, particularly in that portion of the series which I have called Monian, are numerous, discontinuous masses of quartz, as in the Sugar Loaf and Holyhead. There are also, in Anglesey, some still more isolated masses in the shape of quartz-knobssmall outstanding humps of white quartz rock-in the midst of a vast area of schists or ancient tuffs. It is the study of these that has suggested a possible source for a large part of the ancient quartz rocks and quartzites.

Whatever difficulties may have to be got over with regard to the crystalline or colloidal form of the substance, it is certain that from a chemical point of view the quartz of all sedimentary rocks must be derived from such original sources as produce practically pure silica. 'There are, I think, only three such, viz.: igneous rocks, one of whose mineral constituents is quartz, quartz veins and siliceous springs. The first of these has hitherto been almost the only source considered. To get the grains of quartz out of igneous rocks the other minerals have to be separated, and where this is done with such exceptional completeness, as in the case of a white quartzite, some unusual facilities must be supposed. Quartz veins are an obvious source of quartz pebbles, and when the latter are large, as in many Cambrian conglomerates, they seem necessarily derived from this source. As, however, quartz veins are so intimately connected with siliceous springs, both being the result of crystallization or deposit from water carrying silica in solution, they need not be considered separately.

The point, therefore, that I here suggest is that the deposits from ancient silicenus springs are an important source of the quartz of which some of the ancient quartzites and quartz rocks are composed. The starting point of this theory is undoubtedly the structure of the quartzknobs of Anglesey. In that island there are scattered over the surface amongst the most ancient rocks, but not specially related to any particular part of them, a number of white glistening bosses of rock, which look in the distance like a whitewashed cottage only that they are usually somewhat larger. Most of these when examined microscopically show some rounded grains, and they might therefore be mistaken for ordinary quartzites: Their peculiar mode of occurrence, however, calling for more careful study, it is seen that in all there is also present a different structure, which in some belongs to the bulk of the rock or even to the whole. It is what I have called a polysonal structure. The whole area of the slide is divided up into a mesh work by clear lines, the interior of the polygons thus produced being spotted over by the minute inclusions common in quartz, which are arranged to a certain extent in relation to the edges of the polygons. (Fig. I.) Under polarized light it is seen that each polygon is a single crystal, whose crinkly or "sutural" outlines so interlock with those of the adjacent crystals that they could only have formed in situ. (Fig. 2.) In fact, except for all the crystals being quartz, the structure resembles the granitic. Where such a structure is in small proportion to the whole it might be considered secondary, but where elsewhere the bulk of the rock is of this kind we cannot so consider it. If, however, the several crystals were to separate along these polygonal lines, they might easily be rounded into the pebble form. There is, therefore, no objection that I can see to considering the crystalline portion the primary, and the rounded grains the secondary structure. This conclusion is confirmed by certain peculiarities in the mode of occurrence. Thus in one example, which shows the polygonal structure with the greatest clearness, as we approach the knob from a distance we find the surrounding schists first veined with quartz, then the quartz veins become more abundant, then predominate over the schist, and finally at the knob itself nothing is present but the pure white quartz full of minute bubbles. Thus the knob is intimately connected with veins and has no relation to any bedded rock. In another case there is a kind of rock crossing the stratification of the schists and connected at the top with a once horizontal mass which is parallel to the stratification. These cases I take to be illustrations of the pipes of the siliceous springs.

Looking at the matter from the other side there seems no good reason to believe that such siliceous deposits as those of the Yellowstone Park and of Rotomahana should be confined to our own epoch, and yet where are 
we to find these representatives in more ancient periods if not in such quartz masses as these? There is this difficulty, however, that the sample of the white terrace of Rotomahana that I have examined has no action upon polarized light and is not, therefore, crystalline. But this difficulty is easily explained by comparison with the glassy form of igneous rocks which does not prevent us looking on other rocks as igneous which are crystalline. An example of a pure quartz vein cutting like a dyke the igneous rocks of Chamwood Forest, Leicestershire, which I have examined, shows a microcrystalline structure, very like that of some felsites, especially the older ones. The association of rounded grains of quartz should also no more surprise us than the association of volcanic ashes with eruptive crystalline rocks and association so intimate in the case of some of the Italian volcanoes that it is

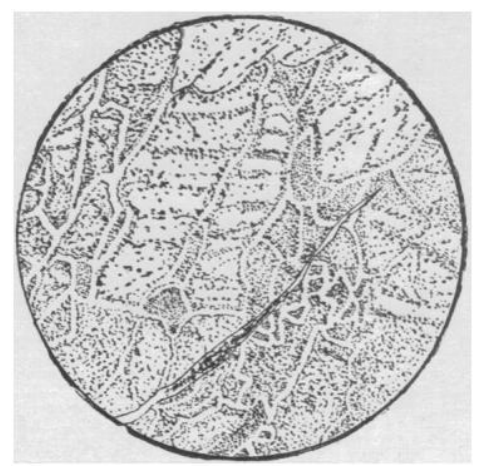

Fig. I. Structure of a quartz knob in Anglesey seen under ordinary light.

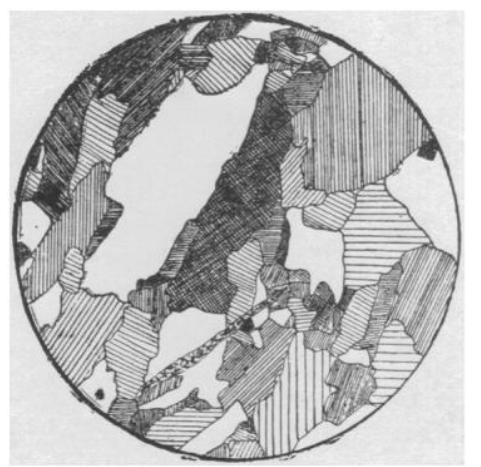

Fig. 2. Structure of the same seen between crossed nicols.

sometimes difficult to say where one begins and the other ends; for instance, on the island of Ischia I have observed an obsidian crowded with fragments. By this comparison I would not be understood to imply that these quartz knobs are "igneous," but I think they are of hydrothermal origin, as to some extent also are true igneous rocks.

With regard to the larger masses, if they are not of the nature of quartz veins, as many of the gold bearing reefs may be, they are probably derived by attrition, etc., from original siliceous deposits of the same nature as the above, and in this case they are not fragments of a dislocated bed of continuous sandstone, but mark the proximate sites of previously existing siliceous springs, - the sum total of the deposits from such bearing naturally no pro- portion to the size of the rocks up which they have been brought, but being of far greater size. Even the continuous beds of quartzite having an ordinary stratified arrangement may be derived in the first place from such sources, which will in part account for their whiteness.

There are one or two subsidiary observations which lend some support to this contention. As originally noted by I)r. R. D. Irving, the quartz grains of the Huronian quartzites are cemented by an additional growth of quartz around them, and though this quartz is of course of secondary origin, it shows that siliceous water was percolating rocks in the district. But of more importance is the occurrence of pebbles of jasper, and large ones of pure vein quartz in these Huronian quartzites. The former mineral is not an original constituent of quartz bearing plutonic rocks, but it is undoubtedly formed in the wet way. Similar jasper pebbles are formed also in Anglesey in association with limestones where these are themselves associated with the quartz rocks. There are also large tabular crystals of platz hæmatite in the white Potsdam quartzite near Philadelphia. Thus the associates of the quartz in such quartzites are not those common in granites, etc., but those which point to aqueous agencies.

Again, though more rarely. we find limestones associated with the quartzites which have the same peculiarities of distribution and mode of occurrence. 'These show no traces of organic structure, though there is no reason that I can see why it should not be present even in Pre-Cambrian rocks, but in some cases they do show very decided traces of a tufaceous origin. One example in Anglesey being especially remarkable, as it consists of a compound oolite, layer after layer of irregularly deposited calcite forming the coats, and a pair of the smaller bodies being sometimes surrounded by other coats embracing the two. There are also lenticular patches of bedded limestone probably like the larger quartz masses derived from these-a similar patch of tufaceous-looking, non-organic, limestone occurs in the Huronian series north of Lake Huron.

For these various reasons it seems to me that we must at least consider the possibility of the original source of the quartz in these early quartzites being the deposit from siliceous springs, possibly from the more crystalline character, bursting out under somewhat different conditions as to pressure, etc., from modern ones, and from the abundance of such quartzites we may look upon the later Pre-Cambrian period as characterized by the abundance of such springs, an idea not at all inconsistent with the supposed volcanic origin of many of the so-called Archæan rocks.

- Messrs. Frederick Warne \& Co., New York, will immediately commence the publication of the "Library of Natural History," the first installments of which-will compose "The Royal Natural History," to be edited by Mr. Richard Lydekker, B. A., F. G. S., F. Z. S., who is already well known to naturalists as a scientist and the author of several works on mammalia, etc. This will form, when completed, an entirely new general natural history, thoroughly abreast of the age; full, accurate and readable, anecdotic, and conveniently arranged. It will contain some 1600 illustrations and a series of 72 colored plates. This work will occupy thirty-six monthly numbers, and will be sold at fifty cents a number. Full details will be contained in an illustrated prospectus now. in hand. 